How to Perform Ultrasonography in Endometriosis

Stefano Guerriero George Condous Juan Luis Alcázar Editors 
Stefano Guerriero

George Condous • Juan Luis Alcázar

Editors

\section{How to Perform \\ Ultrasonography in Endometriosis}

算 Springer 
Editors

Stefano Guerriero

Department of Obstetrics and

Gynecology

University of Cagliari

Cagliari

Italy

Juan Luis Alcázar

Obstetrics and Gynecology Department

University of Navarra

Pamplona

Spain

\section{George Condous}

Acute Gynaecology, Early Pregnancy

and Advanced Endosurgery Unit

Sydney Medical School Nepean

University of Sydney

Nepean Hospital

Sydney, Australia

\author{
ISBN 978-3-319-71137-9 \\ ISBN 978-3-319-71138-6 (eBook) \\ https://doi.org/10.1007/978-3-319-71138-6
}

Library of Congress Control Number: 2018950453

D Springer International Publishing AG, part of Springer Nature 2018

This work is subject to copyright. All rights are reserved by the Publisher, whether the whole or part of the material is concerned, specifically the rights of translation, reprinting, reuse of illustrations, recitation, broadcasting, reproduction on microfilms or in any other physical way, and transmission or information storage and retrieval, electronic adaptation, computer software, or by similar or dissimilar methodology now known or hereafter developed.

The use of general descriptive names, registered names, trademarks, service marks, etc. in this publication does not imply, even in the absence of a specific statement, that such names are exempt from the relevant protective laws and regulations and therefore free for general use.

The publisher, the authors and the editors are safe to assume that the advice and information in this book are believed to be true and accurate at the date of publication. Neither the publisher nor the authors or the editors give a warranty, express or implied, with respect to the material contained herein or for any errors or omissions that may have been made. The publisher remains neutral with regard to jurisdictional claims in published maps and institutional affiliations.

Printed on acid-free paper

This Springer imprint is published by the registered company Springer Nature Switzerland AG The registered company address is: Gewerbestrasse 11, 6330 Cham, Switzerland 


\section{Contents}

1 Endometriosis: Clinical and Anatomical Considerations ..... 1 Sukhbir S. Singh

2 Medical and Surgical Management of Endometriosis. .......

Errico Zupi, Lucia Lazzeri, and Caterina Exacoustos

3 Standardized Ultrasonographic Diagnostic Protocol to Diagnose Endometriosis Based on the International Deep Endometriosis Analysis (IDEA) Consensus Statement . . . . . . Mathew Leonardi and George Condous

4 Uterine Evaluation Using a Diagnostic Protocol Based on MUSA

Thierry Van den Bosch

5 Ovarian Endometriosis.

Juan Luis Alcázar

6 Soft Marker Evaluation Shannon Reid

7 Ultrasound in the Evaluation of Pouch of Douglas Obliteration. . . . . . . . . . . . $63 \ldots \ldots \ldots$.

Shannon Reid

8 Anterior Compartment Including Ureter. Luca Savelli and Maria Cristina Scifo

9 Uterosacral Ligament Endometriosis Francesco Paolo Giuseppe Leone

10 Forniceal-Vaginal Deep Endometriosis. Stefano Guerriero, Gil Cohen, Silvia Ajossa, Ornella Comparetto, Camilla Ronchetti, Bruno Piras, Alba Piras, and Valerio Mais

11 Rectovaginal Septum Endometriosis. Gernot Hudelist and Kristine Aas-Eng

12 Rectum, Rectosigmoid, and Sigmoid Endometriosis. Manoel Orlando Goncalves, Leandro Accardo de Mattos, and Mauricio S. Abrao 
13 Other Locations of Deep Endometriosis.

Stefano Guerriero, Silvia Ajossa, Ornella Comparetto,

Camilla Ronchetti, Virginia Zanda, Bruno Piras,

Alba Piras, and Valerio Mais

14 Modified Ultrasonographic Techniques

Simone Ferrero, Umberto Leone Roberti Maggiore,

Fabio Barra, and Carolina Scala

15 Additional Radiological Techniques (MRI)

Federica Schirru, Stefano Guerriero, and Luca Saba

16 Biomarkers in Endometriosis

Vicki Nisenblat and M. Louise Hull

17 Clinical Cases and Videos.

Mauricio León, Hugo Sovino, and Juan Luis Alcazar

Index. 